\title{
Do transformational leaders enhance their followers' daily work engagement?
}

\author{
Maria Tims*, Arnold B. Bakker, Despoina Xanthopoulou \\ Erasmus University Rotterdam, Institute of Psychology, Department of Work and Organizational Psychology, Rotterdam, The Netherlands
}

\section{A R T I C L E I N F O}

Available online 2 February 2011

\section{Keywords:}

Diary study

Personal resources

Transformational leadership

Work engagement

\begin{abstract}
A B S T R A C T
This diary study investigated whether and how supervisors' leadership style influences followers' daily work engagement. On the basis of leadership theories and the job demands-resources model, we predicted that a transformational leadership style enhances employees' work engagement through the mediation of self-efficacy and optimism, on a day-to-day basis. Fortytwo employees first filled in a general questionnaire, and then a diary survey over five consecutive workdays. The results of multilevel analyses offered partial support for our hypotheses. Daily transformational leadership related positively to employees' daily engagement, and day-levels of optimism fully mediated this relationship. However, daily self-efficacy did not act as a mediator. These findings expand theory and previous research by illuminating the role of transformational leaders in fostering employee work engagement.
\end{abstract}

(c) 2010 Elsevier Inc. All rights reserved.

The concept of work engagement has gained momentum because of its predictive value for job performance (Bakker, 2009; Schaufeli \& Salanova, 2007). In their recent review, Macey and Schneider (2008) listed various different definitions of work engagement. We follow Schaufeli and Bakker's (2004) operationalization, according to which work engagement is a positive, affective-motivational work-related state that is characterized by vigor, dedication, and absorption. Vigor refers to high levels of energy and mental resilience while working. Dedication refers to a sense of significance, enthusiasm, inspiration, pride, and challenge. Finally, absorption is characterized by being fully concentrated and happily engrossed in one's work, whereby time passes quickly and one has difficulties with detaching from work (Schaufeli \& Bakker, 2004, 2010). We adopt this definition because we agree that work engagement is best conceived as the experience of the work activity, rather than a behavior that is driven by the connection with the work role (Bakker, Schaufeli, Leiter, \& Taris, 2008). Furthermore, this definition encapsulates the concepts' state nature, meaning that engagement is not just a trait-like factor, but may vary even within the same person over time (Sonnentag, 2003; Sonnentag, Dormann, \& Demerouti, 2010).

Previous studies have shown that job resources (e.g., autonomy; for reviews, see Bakker, 2009; Halbesleben, 2010) and personal resources (e.g., self-efficacy; Xanthopoulou, Bakker, Demerouti, \& Schaufeli, 2007; Xanthopoulou, Bakker, Demerouti, \& Schaufeli, 2009a,b), due to their motivational potential, are important antecedents of work engagement. However, as far as we know, the role of the leader in fostering work engagement has received limited research attention. The central aim of the present study was to examine the relationship between transformational leadership and work engagement. We performed a diary study, in order to capture between- and within-person variations in the variables of interest. Specifically, we examined whether daily fluctuations in transformational leadership affect employees' daily work engagement, through employees' daily personal resources (self-efficacy and optimism).

\footnotetext{
* Corresponding author. Erasmus University Rotterdam, Institute of Psychology, Woudestein, T12-59, P.O. Box 1738, 3000 DR Rotterdam, The Netherlands. Tel.: +31 10408 2304; fax: +31104089009.

E-mail address: tims@fsw.eur.nl (M. Tims).
} 


\section{Daily fluctuations}

The majority of previous (cross-sectional and longitudinal) studies treated work engagement as a relatively stable (trait-like) variable across time (Bakker, 2009; Macey \& Schneider, 2008). As such, these studies have solely focused on between-person differences in work engagement. However, and in line with Schaufeli and Bakker's (2004) definition, work engagement may also be viewed as a state that may fluctuate within the same person. In this context, Sonnentag et al. (2010) suggested that generally engaged employees may have off-days, since "not all days are created equally". Indeed, diary studies have shown that daily fluctuations in (job and personal) resources are the most crucial predictors of day-level work engagement over and above employees' average (trait) levels of resources and engagement (Sonnentag, 2003; Xanthopoulou et al., 2009a). This implies that the simultaneous examination of the variables of interest at both the between-person (i.e., as enduring experiences, referred to as "traits") and the within-person level (i.e., as daily states) contributes significantly to our understanding of the psychological processes under study. This complementary approach was followed in the present diary study, where we investigate daily fluctuations of the variables of interest, while controlling for the respective traits.

Next to work engagement, we treat transformational leadership (i.e., consideration and support for followers; Bass, 1985), self-efficacy (i.e., people's expectations of being able to execute desired behaviors and impact their environment successfully; Bandura, 1977), and optimism (i.e., the expectation that positive things will happen; Scheier \& Carver, 1992) as both traits and day-level factors. It is likely to expect that a generally transformational leader, who receives bad news at the beginning of the workday, will need to spend effort in order to deal with this new situation. This effort expenditure may lead to impaired attention and reduced help to his/her subordinates on that day, which is indicative of low transformational leadership. Consequently, subordinates who are generally self-efficacious and optimistic may feel less positive on that day, since they will not receive the leader support they are used to. In turn, this may affect their work engagement on that specific day. It is important to note that transformational leadership (Barling, Weber, \& Kelloway, 1996), self-efficacy (Bandura, 1997) and optimism (Luthans, Avey, Avolio, Norman, \& Combs, 2006; Luthans \& Youssef, 2007) have shown to be malleable and sensitive to training and learning, implying that they may fluctuate within the same person depending on external stimuli. Additionally, previous studies have argued and shown that personal resources like optimism and self-efficacy may fluctuate from their dispositional baseline, even on the day-level (Xanthopoulou, Bakker, Heuven, Demerouti, \& Schaufeli, 2008; Xanthopoulou et al., 2009a).

The importance of examining the proposed psychological processes at the within-person level goes beyond the obvious methodological advantage of capturing day-to-day fluctuations. The added value of such an undertaking is above all theoretical. According to the homological views in theoretical modeling, constructs are expected to operate similarly across different levels of analysis (Kozlowski \& Klein, 2000). Therefore, support for homology of certain relationships across levels of analysis (at the between- and within-person level) adds to the parsimony and breadth of theories, while rejection of homology sets boundaries and indicates the need of theory refinement (Chen, Bliese, \& Mathieu, 2005).

\section{Leadership styles and work engagement}

Bass (1985) differentiated between three broad leadership styles that vary from individual consideration and support for the employee (transformational style) to a proportional exchange between the leader and the employee (transactional style), or to no interest at all for the employee (laissez-faire style). We do not expect that the latter two leadership styles contribute to employees' work engagement substantially, because they lack motivational power and inspirational appeal. Indirect evidence for this contention comes from an experimental study by van Vugt, Jepson, Hart, and de Cremer (2004). Participants were randomly assigned to one of three groups and took part in three investment task trials. The authors manipulated the content of the messages sent by the leader to the group members to simulate either a transactional, transformational, or laissez-faire leadership style. After the task trials, individuals were asked whether they wanted to stay in the same group or join a different group for a subsequent task. The results suggested that participants were more likely to leave the group when they were in the condition with the transactional or the laissez-faire leader, in contrast with the transformational leader. When confronted with a transactional leader, group members were unhappy with the limited amount of control they had over the decision processes, while when confronted with a laissez-faire leader participants did have control, but they were not motivated to invest additional effort.

Furthermore, transactional leaders motivate only to get the work done and reward employees accordingly (Bass, 1985), but external rewards (particularly those that are given after finishing a specific task) have been consistently found to have a negative effect on intrinsic motivation (for a meta-analysis, see Deci, Koestner, \& Ryan, 1999). Finally, several studies provide additional evidence for the destructiveness of the laissez-faire leadership style. Skogstad, Einarsen, Torsheim, Aasland, and Hetland (2007) found that this 'leaderless' leadership style was positively associated with job stressors such as role ambiguity, role conflict and conflict with co-workers, while Hauge, Skogstad, and Einarsen (2007) supported its positive relationship with bullying at work. To conclude, previous research favours our decision to focus on transformational leadership in relation to work engagement.

\section{Transformational leadership and work engagement}

Transformational leadership is defined as leadership behavior that transforms the norms and values of the employees, whereby the leader motivates the workers to perform beyond their own expectations (Yukl, 1989). This leadership style focuses on the enhancement of the followers' involvement with the goals of their organization (Bass, 1985). A central aspect of this leadership style is the inspiring vision of the supervisor (den Hartog, Koopman, \& van Muijen, 1997). 
Transformational leadership is traditionally divided into four components, namely (1) inspirational motivation; (2) idealized influence; (3) individual consideration; and (4) intellectual stimulation (Bass \& Avolio, 1990; Chemers, 2000; den Hartog et al., 1997). Inspirational motivation focuses on the communication of an appealing vision of the future and the use of symbols to articulate this vision (den Hartog et al., 1997). In other words, the supervisor is optimistic and enthusiastic about the future (Bono \& Judge, 2004). Idealized influence refers to behaviors like showing that benefits of the group are more important than benefits of the individual, demonstrating high ethical norms, and being a role model for the subordinates (Bono \& Judge, 2004). Inspirational motivation and idealized influence together are also called "charisma". Charismatic leaders have a positive influence on their subordinates and can change the self-focus of the employees to a collective focus (Yorges, Weiss, \& Strickland, 1999). As a result, subordinates become more involved with the vision of the leader and are willing to make sacrifices for that vision (House \& Howell, 1992).

The third component of transformational leadership, individual consideration, refers to coaching, supporting and stimulating subordinates. The supervisor acknowledges followers' feelings and emotions and their need to grow and develop themselves (den Hartog et al., 1997). Employees are seen as unique individuals who need specific, individual attention that is congruent with the developmental phase they are in (Avolio \& Bass, 1995). The fourth and last component of transformational leadership is called intellectual stimulation, which means that the supervisor challenges the subordinate to see problems from a different perspective. In this way, the supervisor makes the workers active thinkers within the organization and consequently, the employees become more involved with the organization.

It has been found that employees' feelings of involvement, cohesiveness, commitment, potency, and performance are enhanced by the transformational leadership style (Shamir, House, \& Arthur, 1993). An employee who receives support, inspiration and quality coaching from the supervisor, is likely to experience work as more challenging, involving and satisfying, and consequently, to become highly engaged with the job tasks. Taking into account that satisfaction with one's co-workers is related to work engagement (Avery, McKay, \& Wilson, 2007), it is conceivable that satisfaction that arises from working with a transformational leader may have similar results. On the basis of these findings and leadership theory we predict that the transformational leadership style enhances employees' work engagement, or formally:

Hypothesis 1. Day-level transformational leadership has a positive relationship with followers' day-level work engagement.

\section{Transformational leadership and personal resources}

One possible reason why transformational leaders have a positive impact on their followers' engagement is that the leaders' inspiration and stimulation may enhance employees' personal resources. Personal resources are aspects of the self that are generally linked to resiliency (Hobfoll, Johnson, Ennis, \& Jackson, 2003). In the present study, we focus on two typical types of personal resources namely, self-efficacy (Bandura, 1977), and optimism (Scheier \& Carver, 1992). Employees working in a resourceful work environment (e.g., characterized by quality coaching, feedback, support) are likely to feel optimistic and to believe that they are able to achieve their work goals. Consequently, their work engagement may be enhanced (Xanthopoulou et al., 2007). Indeed, recent studies have shown that personal resources mediate the relationship between job resources and work engagement (Llorens, Schaufeli, Bakker, \& Salanova, 2007; Xanthopoulou et al., 2009a). In line with the above, we expect that personal resources may also explain the link between transformational leadership and work engagement.

Transformational leadership is expected to enhance employees' self-efficacy for two reasons. First, Shamir et al. (1993) proposed that transformational leaders enhance their subordinates' self-efficacy by expressing high expectations for them and confidence in their abilities to meet such expectations. Second, transformational leaders offer mastery experiences to their employees, and use social persuasion to convince them of their capacities (Bandura, 1977). Transformational leaders delegate inspiring tasks to their employees and give them more opportunities to experience mastery. Mastery experiences boost employees' self-efficacy because they provide positive feedback about their efforts and performance (Pajares, 2002). Next, transformational leaders, by using social persuasion, enhance employees' beliefs about their capacities to be successful in a given task (Pajares, 2002), which consequently may increase employees' confidence and self-efficacy.

Empirical studies supported the impact of transformational leadership on self-efficacy. For instance, Kirkpatrick and Locke (1996) examined in a laboratory study among 282 students the relationship between transformational leadership and selfefficacy. The leaders in this study were trained actors who behaved either transformational (inspiring a quality vision) or non transformational (no vision). Results suggested that the transformational leader had an indirect effect on followers' performance (quality) through self-efficacy. Based on the above theoretical analysis and empirical evidence, we formulated our next hypothesis:

Hypothesis 2. Day-level self-efficacy mediates the relationship between day-level transformational leadership and day-level work engagement.

In a similar vein, optimism may be enhanced by the transformational leadership style. Transformational leaders are known to be optimistic themselves. McColl-Kennedy and Anderson (2002) demonstrated that transformational supervisors increased the level of optimism of their employees directly. Furthermore, they found that optimism of the follower mediated the relationship between transformational leadership and employee job performance. These findings imply that transformational leaders provide a challenging and optimistic view about the future, which motivates employees to perceive the future optimistically too. A possible 
explanation can be found in contagion theories (Bakker, Westman, \& van Emmerik, 2009; Hatfield, Cacioppo, \& Rapson, 1994). Contagion occurs when an employee pays attention to the emotional expressions of the leader and unintentionally mimics them. An employee who unintentionally mimics the optimism expressed by his/her transformational leader, is likely to end up feeling optimistic as well. In this context, Bono, Jackson Foldes, Vinson, and Muros (2007) conducted an experience sampling study to examine the role of leaders in employees' emotional experiences. They found that employees who were supervised by transformational leaders experienced more positive emotions throughout the course of their workday including optimism, happiness, and enthusiasm. Finally, Xanthopoulou et al. (2009a) in their diary study among fast-food restaurant employees found that quality coaching from the supervisor made employees feel more optimistic at work, which in turn increased their day-levels of work engagement. Nevertheless, we are aware of no studies so far that examined optimism as a function of transformational leadership style and its relationship with work engagement. This leads us to formulate our third and final hypothesis:

Hypothesis 3. Day-level optimism mediates the relationship between day-level transformational leadership style and day-level work engagement of the employee.

\section{Control variables}

The trait (between-person) measures of the variables of interest were used as control variables in this study, because the way employees generally react to their work or the general beliefs about themselves may also affect their momentary states (George, 1991; Sonnentag et al., 2010). In our main analyses, we also controlled for day-levels of job resources, not only because job resources are crucial determinants of work engagement (Halbesleben, 2010), but also because they have been found to function as triggers of positive mood at work (Schaufeli \& van Rhenen, 2006). Thus, by controlling for daily job resources, we could diminish potential 'good day' effects. Fig. 1 graphically presents the research design and hypotheses of this study.

\section{Method}

\subsection{Participants and procedure}

Participants were employed at two different organizations in The Netherlands. Most participants worked as consultants at an agency for temporary work (84\%), while the rest worked at an industrial consultancy agency (16\%). In both organizations a contact person made sure that every participant referred to and rated a different leader. Participants were asked to fill in first a general questionnaire and then a daily survey for five consecutive workdays. All survey packages were sent to the participants via e-mail. The survey package was made in an Excel file, with six tabs containing the general questionnaire and each of the five daily surveys. On the front page there was an information letter, in which the study was introduced and confidentiality of the responses was emphasized. Participants were instructed to fill out the questionnaire before the diary, and to complete the diary surveys over five

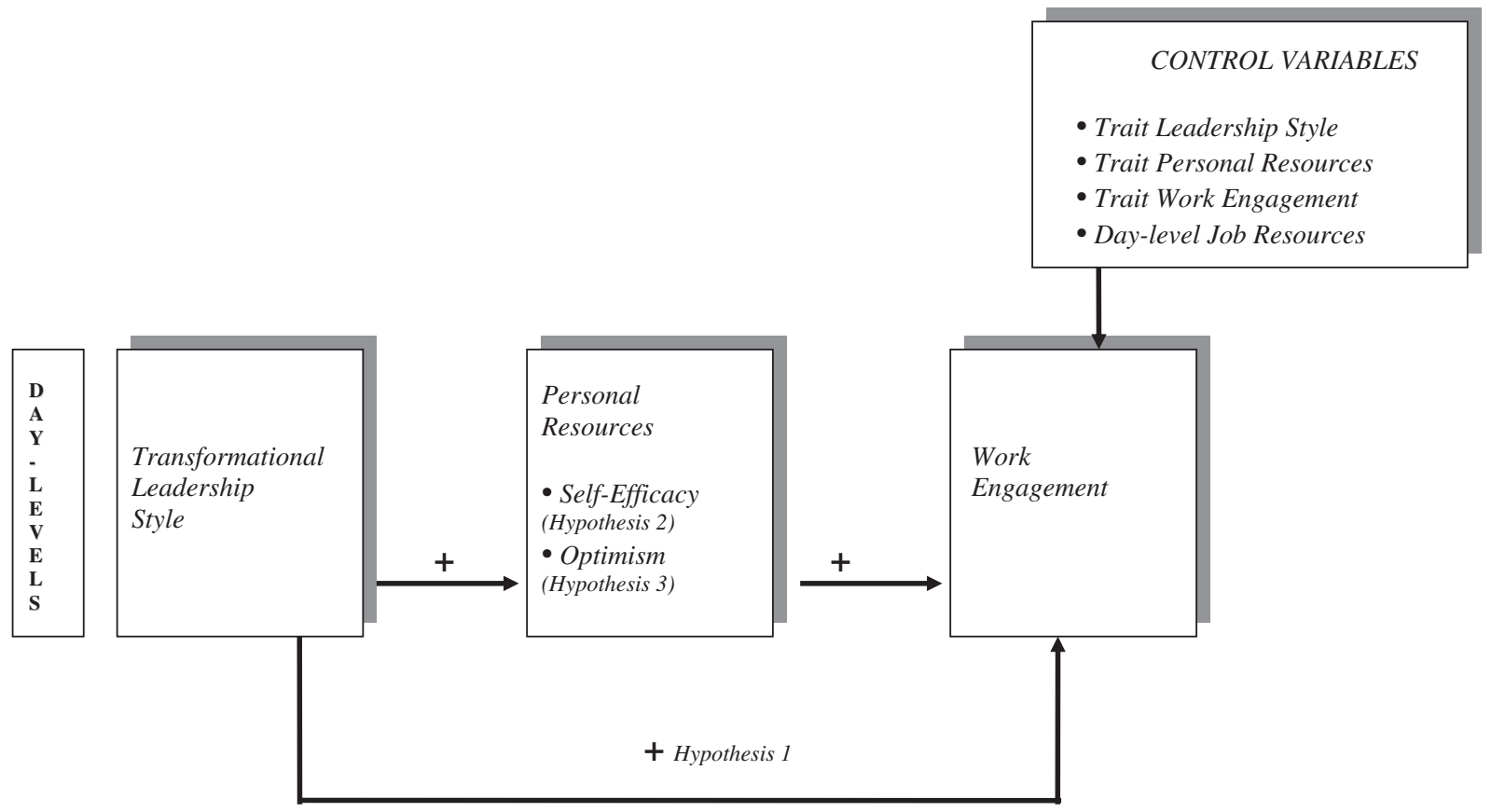

Fig. 1. The study design and hypotheses. 
consecutive workdays, at the end of the workday. Participants could type their answers directly into the respective excel sheet. When all surveys were completed, participants e-mailed the file with the questionnaires to the first author.

Forty-five employees out of 55 that were initially approached participated in the study (response rate of $82 \%$ ). We excluded three participants because of incomplete surveys, which resulted in 42 usable questionnaires and diary surveys. The final sample included 15 males (33.71\%) and 27 females (64.29\%). Participant's mean age was 32.44 years $(S D=8.62)$ and their organizational tenure was on average 2.79 years $(S D=2.32)$. Most employees lived together with a partner $(35.71 \%)$ and had completed higher vocational education (95.2\%).

\subsection{Measures}

\subsubsection{Questionnaire data}

The questionnaire measured trait work engagement, trait transformational leadership style, and trait personal resources (i.e., self-efficacy and optimism), as well as demographic variables.

Trait work engagement was measured with the short, 9-item version of the Utrecht Work Engagement Scale (UWES; Schaufeli, Bakker, \& Salanova, 2006). This scale includes three items for each of the three underlying dimensions of work engagement. Example items are: “At work, I feel bursting with energy" (vigor); "I am enthusiastic about my job” (dedication); and "I get carried away when I am working” (absorption). A 7-point scale was used with answers ranging from 0 (never) to 6 (always). We computed an overall work engagement score as recommended by Schaufeli et al. (2006; Cronbach's $\alpha=.89$ ).

Trait transformational leadership style was measured with the 12-item Dutch version (Stuart, 2005) of the Multifactor Leadership Questionnaire (MLQ; Bass \& Avolio, 1990). Employees filled out this scale having in mind their direct supervisor. It is important to note that all participants had a different supervisor as a reference point. The scale includes three items for each of the four sub-dimensions of transformational leadership, namely intellectual stimulation (e.g., "My supervisor stimulates me to solve problems by myself"), inspirational motivation (e.g., "My supervisor keeps the morale of the department high"), idealized influence (e.g., "My supervisor creates the feeling that we work on an important assignment"), and individual consideration (e.g., "My supervisor is really interested in my personal development"). Participants rated how often their supervisor showed the specific behaviors on a 5-point scale ranging from 0 (never) to 4 (often, almost always). In our analyses, we used an overall transformational leadership style score, as proposed by previous researchers (Bono et al., 2007; Bycio, Hackett, \& Allen, 1995; Cronbach's $\alpha=.85$ ). This decision was further supported by the fact that the four sub-scales were highly intercorrelated in our sample (all $\left.r^{\prime} \mathbf{s}>.78\right)$.

Trait self-efficacy was measured with four items adapted from Schwartzer and Jerusalem's (1995) scale (Cronbach's $\alpha=.78$ ). The response categories vary between 1 (totally disagree) and 5 (totally agree). An example item is: "I trust I can handle sudden events effectively". Trait optimism was measured with three items (e.g., "I usually expect the best in insecure times") adapted from the Life Orientation Test - Revised (Scheier, Carver, \& Bridges, 1994). The anchors varied between 1 (totally disagree) and 5 (totally agree) and Cronbach's alpha was .67.

Demographic variables were assessed with one item each for age, gender, marital status and level of education.

\subsubsection{Diary survey data}

In each of the five diary surveys participants reported on the study variables with regard to the specific workday. To measure day-levels of the variables of interest, we used the exact same scales used in the general questionnaire adapted such as to refer to the specific day.

Day-level work engagement was measured with the state 9-item day-level version (see Xanthopoulou et al., 2009a) of the UWES (Schaufeli et al., 2006). Examples of items are: "Today during work, I felt fit and strong" (vigor), "Today, I was very enthusiastic about my work" (dedication), and "Today, I completely lost myself in my work" (absorption). Answering categories ranged from 1 (no, not at all) to 7 (yes, completely right). Cronbach's alphas ranged from .89 to $.95(M=.92)$ across the five occasions.

Day-level transformational leadership was measured with the same 12 items from the MLQ (Stuart, 2005) that were used in the general questionnaire. An example item from the intellectual stimulation sub-scale is: "Today, my supervisor stimulated me to solve problems myself". A 7-point scale was used ranging from 1 (no, not at all) to 7 (yes, completely right). Cronbach's alphas ranged from .90 to $.96(\mathrm{M}=.93)$ across the five days.

Day-level self-efficacy was measured with the four items from Schwartzer and Jerusalem's (1995) scale that were adapted so as to refer to the specific workday (e.g., "Today, I trusted that I could handle unexpected events effectively"). The answering categories ranged from 1 (totally disagree) to 5 (totally agree). Cronbach's alphas ranged from .65 to .80 ( $\mathrm{M}=.77$ ) across the five occasions. Day-level optimism was also measured with the same three items (e.g., "Today, I expected more positive things would happen than negative things") adapted from the Life Orientation Test - Revised (Scheier et al., 1994) and transformed to a state version. The responses could vary between 1 (totally disagree) and 5 (totally agree). Cronbach's alphas varied between .70 and .80 $(\mathrm{M}=.76)$ across the five days.

Day-level job resources was measured with one item capturing different types of resources that have been recognized as crucial for the majority of employees in previous studies (for a meta-analysis, see Halbesleben, 2010). Particularly, in each of the five diary surveys we added a part where we explained to participants what job resources are (i.e., means to deal with job demands, characteristics of the job that induce personal learning and development) and we gave examples of resources (i.e., autonomy, good communication, task variety). Next, we asked them to rate $(1=$ very low; $10=$ very high $)$ the level of job resources they had experienced during each specific day the study took place. 


\subsubsection{Strategy of analysis}

Our repeated measures data can be viewed as multilevel data, with repeated measurements (days) nested within individuals. This leads to a two-level model with the days at the first-level (level $1 ; N=210$ study occasions) and the individual persons at the second-level (level 2; $N=42$ participants). Multilevel analysis with the MlwiN programme (Rashbash, Browne, Healy, Cameron, \& Charlton, 2000) was applied. On the basis of Maas and Hox's (2005) rule of thumb for power in multilevel modeling (i.e., a minimum of 30 cases at level 2), it may be suggested that the sample of the present study is adequate for robust estimations.

Multilevel analysis accounts for dependencies among the levels of analysis due to repeated measures and, therefore is more appropriate than other techniques that assume independent observations (Dierdorff \& Ellington, 2008). Furthermore, this analytical method allows modeling simultaneously within- and between-group variance in the examined factors (Dierdorff \& Ellington, 2008). In the present study, predictor variables at the day-level (level 1; i.e., day-level leadership style, day-level personal resources and day-level job resources) were centered to the respective person mean to strictly reflect intra-individual processes. Predictor variables at the person-level (level 2; i.e., trait personal resources, trait work engagement and trait transformational leadership style) were centered around the grand mean. Centering day-level variables at the person mean allows removing the between-person variance from these variables. This eliminates the role of stable differences in explaining participant's day-levels of perceived leadership style, personal resources and job resources (see also Sonnentag \& Niessen, 2008).

\section{Results}

\subsection{Descriptive statistics}

Table 1 presents mean scores, standard deviations and correlations among the study variables. Demographic variables (Table 1) were non-significantly related with the study variables and thus, were excluded from further analyses.

\subsection{Supporting the use of multilevel modeling}

Before proceeding with the test of our hypotheses, it is imperative to provide statistical evidence for the use of multilevel modeling. Namely, it is important to show that our dependent variable (i.e., day-level work engagement) exhibits sufficient variability at both levels of analysis (between- and within-person; Dierdorff \& Ellington, 2008). We applied a deviance $(-2 \times \log$ ) difference test comparing an intercept-only model with one level (i.e., only within-person) to an intercept-only model with two levels (i.e., between- and within-person) and with daily work engagement as the dependent variable. This analysis shows whether a model with two levels explains the data better than a model with one level, and allows partitioning the total variance in day-level work engagement into within and between components (Dierdorff \& Ellington, 2008). Results showed that the model with two levels fitted significantly better to the data than the model with one level $(\Delta-2 \times \log =23.03, p<.001)$. Next, on the basis of the intercept-only model, we calculated the intra-class correlation $(\rho)$. The intra-class correlation explains how much of the variance may be attributed to the different levels of analysis. If the amount of within-person variance is very low, it would mean that work engagement does not vary significantly from one day to another. The findings showed that $28 \%$ of the variance is attributable to between-person fluctuations and $72 \%$ to within-person fluctuations. These results imply that there is enough variance attributed at both between- and within-person variance in day-level work engagement, thus supporting the use of multilevel modeling in our study. Additional analyses also supported significant daily fluctuations in the predictor variables (for day-level

Table 1

Means, standard deviations and correlations among study variables ( $\mathrm{N}=42$ employees; and $\mathrm{N}=210$ occasions $)$.

\begin{tabular}{|c|c|c|c|c|c|c|c|c|c|c|c|c|c|c|c|}
\hline & & M & SD & 1 & 2 & 3 & 4 & 5 & 6 & 7 & 8 & 9 & 10 & 11 & 12 \\
\hline 1 & Age & 32.44 & 8.62 & - & & & & & & & & & & & \\
\hline 2 & Gender & 1.64 & .48 & $-.39^{*}$ & - & & & & & & & & & & \\
\hline 3 & Education & 6.76 & 1.78 & -.16 & .18 & - & & & & & & & & & \\
\hline 4 & Trait work engagement & 4.20 & .81 & .03 & .01 & -.15 & - & & & & & & & & \\
\hline 5 & Trait transf. leadership style & 3.07 & .56 & .01 & .02 & -.05 & $.35^{*}$ & - & & & & & & & \\
\hline 6 & Trait self-efficacy & 3.79 & .63 & .09 & -.16 & -.21 & $.52^{* *}$ & .27 & - & & & & & & \\
\hline 7 & Trait optimism & 4.66 & .60 & -.09 & -.03 & .11 & $.31 *$ & $.59^{* *}$ & $.34^{*}$ & - & & & & & \\
\hline 8 & Day-level job resources & 6.62 & .75 & .05 & .04 & .24 & .02 & .01 & -.15 & -.11 & - & & & & \\
\hline 9 & Day-level transf. leadership style & 3.65 & .96 & -.01 & -.06 & -.23 & .22 & $.35^{*}$ & -.10 & .03 & -.05 & - & & & \\
\hline 10 & Day-level self-efficacy & 3.65 & .48 & $-.44^{* *}$ & .11 & .19 & .20 & $.34 *$ & .18 & $.35^{*}$ & .02 & .26 & - & & \\
\hline 11 & Day-level optimism & 4.03 & .49 & -.17 & .14 & .15 & .27 & $.50^{* *}$ & -.05 & $.41^{* *}$ & .07 & $.47^{* *}$ & $.62^{* *}$ & - & \\
\hline 12 & Day-level work engagement & 4.87 & .66 & .16 & .02 & -.11 & $.52^{* *}$ & $.43^{* *}$ & .10 & .17 & .09 & $.45^{* *}$ & $.38^{*}$ & $.52^{* *}$ & - \\
\hline
\end{tabular}

Note. Day-level variables were averaged across 5 days; transf. $=$ transformational.

* $p<.05$.

** $p<.01$. 
transformational leadership style: $\rho=.25$ suggesting that $75 \%$ of the variation is attributable to within-person variations; for day-level optimism: $\rho=.23$ suggesting that $77 \%$ of the variance is attributable to within-person variations; and for day-level self-efficacy: $\rho=.37$, suggesting that $63 \%$ of the variation is attributable to within-person variations). These results emphasize that the multilevel structure of our data should be taken into account while testing the study hypotheses.

\subsection{Testing Hypothesis 1}

Hypothesis 1 proposes that day-level transformational leadership is positively related to employees' daily work engagement. This hypothesis is actually a prerequisite condition for testing the mediation Hypotheses 2 and 3 (Baron \& Kenny, 1986). If the relationship between day-level transformational leadership and day-level work engagement is not supported, the hypotheses of mediation are automatically rejected. As shown in Table 2, results supported the significant positive relationship between daylevel transformational leadership style and day-level work engagement $(\gamma=.14, S E=.06, t=2.33, p<.05)$. Thus, Hypothesis 1 is confirmed.

\subsection{Testing Hypothesis 2: Day-level self-efficacy as a mediator}

According to Hypothesis 2, day-level self-efficacy mediates the relationship between day-level transformational leadership and employees' daily work engagement. Following Baron and Kenny (1986), we examined the required conditions for mediation: a) the predictor should be related to the mediator, $b$ ) the mediator should be related to the outcome, and c) the predictor-outcome relationship becomes non-significant (full mediation), or becomes significantly weaker (partial mediation) after the inclusion of the mediator. To examine the significance of the mediating effects we applied the Sobel $z$-test.

To test the first condition (i.e., whether day-level transformational leadership is significantly related to day-level self-efficacy), we examined three models: a Null (intercept-only) model; Model 1 (in which we controlled for trait self-efficacy); and Model 2 (where day-level transformational leadership style was added). Results showed that day-level leadership style was not significantly related to day-level self-efficacy $(\gamma=.038, S E=.036 ; t=1.06, n s)$. In other words, the first condition for the test of mediation is not supported, therefore Hypothesis 2 is rejected. Day-level self-efficacy cannot function as a mediator in the relationship between day-level transformational leadership and day-level work engagement. Nevertheless, it is interesting to note that day-level self-efficacy was significantly related to day-level work engagement $(\gamma=.559, S E=.113, t=4.95, p<.001)$.

\subsection{Testing Hypothesis 3: Day-level optimism as a mediator}

According to Hypothesis 3, day-level optimism mediates the relationship between day-level transformational leadership and day-level work engagement. To test this hypothesis, we followed the same procedure as for Hypothesis 2. In order to test the first condition, we examined the following models: the Null model (intercept-only); Model 1 (in which we controlled for trait optimism); and Model 2 (where day-level transformational leadership style was added). As expected, results supported the positive relationship between day-level transformational leadership and day-level optimism $(\gamma=.125, S E=.044, t=2.84$, $p<.01$ ).

To test whether the second condition for mediation (i.e., day-level optimism is significantly related to day-level work engagement of the employee) is also met, we tested the following three models: (1) the Null model, where day-level work engagement is the dependent variable; (2) Model 1, in which we controlled for trait work engagement; and (3) Model 2, in which

Table 2

Multilevel estimates of models predicting day-level work engagement ( $\mathrm{N}=42$ employees, and $\mathrm{N}=210$ occasions).

\begin{tabular}{|c|c|c|c|c|c|c|c|c|c|c|c|c|}
\hline \multirow{2}{*}{$\frac{\text { Model: }}{\text { Variables }}$} & \multicolumn{3}{|c|}{ Null } & \multicolumn{3}{|c|}{1} & \multicolumn{3}{|c|}{2} & \multicolumn{3}{|c|}{3} \\
\hline & Estimate & SE & $\mathrm{t}$ & Estimate & $S E$ & $\mathrm{t}$ & Estimate & $S E$ & $\mathrm{t}$ & Estimate & $S E$ & $\mathrm{t}$ \\
\hline Intercept & 4.86 & .10 & $48.60^{* * *}$ & 4.75 & .10 & $47.50^{\text {*** }}$ & 4.76 & .10 & $47.60^{* * *}$ & 4.76 & .09 & $52.89^{* * *}$ \\
\hline Trait work engagement & & & & .46 & .15 & $3.07^{* *}$ & .46 & .15 & $3.07^{* *}$ & .45 & .15 & $3.00^{* *}$ \\
\hline Trait transform. leadership & & & & .53 & .22 & $2.41^{*}$ & .52 & .21 & $2.48^{*}$ & .52 & .21 & $2.48^{*}$ \\
\hline Trait Optimism & & & & -.18 & .20 & -.90 & -.18 & .20 & -.90 & -.18 & .20 & -.90 \\
\hline Trait self-efficacy & & & & -.25 & .20 & -1.25 & -.25 & .20 & -1.25 & -.25 & .20 & -1.25 \\
\hline Day-level job resources & & & & .04 & .04 & 1.00 & .04 & .04 & 1.00 & .10 & .04 & $2.50 *$ \\
\hline Day-level transform. leadership & & & & & & & .14 & .06 & $2.33^{*}$ & .09 & .06 & 1.5 \\
\hline Day-level optimism & & & & & & & & & & .35 & .11 & $3.18^{* *}$ \\
\hline$-2 \times \log$ & & & 559.70 & & & 399.33 & & & 392.73 & & & 382.95 \\
\hline$\Delta-2 \times \log$ & & & & & & $160.37^{* * *}$ & & & $6.60 *$ & & & $9.78^{* * *}$ \\
\hline df & & & & & & 5 & & & 1 & & & 1 \\
\hline & & & & & & $\mathrm{R}^{2}$ & & & $\mathrm{R}^{2}$ & & & $\mathrm{R}^{2}$ \\
\hline Level 1 (within-person) variance & .72 & .08 & & .66 & .09 & $8 \%$ & .64 & .09 & $11 \%$ & .60 & .08 & $17 \%$ \\
\hline Level 2 (between-person) variance & .28 & .10 & & .19 & .09 & $32 \%$ & .18 & .08 & $36 \%$ & .18 & .08 & $36 \%$ \\
\hline
\end{tabular}

$* * * \quad p<.001$

** $p<.01$.

$* p<.05$. 
the predictor day-level optimism was added. The results showed that there was a significant relationship between day-level optimism and day-level work engagement of the employee $(\gamma=.297, S E=.094, t=3.16, p<.001)$. This suggests that day-level optimism may function as a mediator in the relationship between day-level transformational leadership style and day-level work engagement. To test Hypothesis 3, we examined the four models presented in Table 2. Particularly, we tested: (1) a Null model (intercept-only), in which day-level work engagement is the dependent variable; (2) Model 1, in which we controlled for trait work engagement, trait transformational leadership, trait personal resources (self-efficacy and optimism) and day-level job resources; (3) Model 2, in which we added the predictor (i.e., day-level transformational leadership), and (4) Model 3, in which we added the mediator (i.e., day-level optimism). Table 2 presents the unstandardized estimates, standard errors, and $t$ values. Also, intercept variances at the day-level and at the person-level are displayed, and explained variance is calculated (Hox, 2002).

Table 2 shows that after the inclusion of day-level optimism in the equation, the significant direct relationship between daily transformational leadership style and daily work engagement turned to non-significant ( from $\gamma=.14, S E=.06, t=2.33, p<.05$ to $\gamma=.09, S E=.06, t=1.50, n s)$. Application of the Sobel test showed that the reduction in the magnitude of the direct effect was significant $(z=2.12, p<.05)$, suggesting that day-level optimism fully mediates the relationship between transformational leadership and work engagement of the employee at the day-level. To conclude, Hypothesis 3 was supported. The positive direct effect of trait work engagement on daily level of work engagement $(\gamma=.45, S E=.15, t=3.00, p<.01)$ is also worth mentioning (Table 2). This finding indicates that employees who are generally engaged are also more likely to be engaged on a daily basis.

\subsection{Alternative models}

In order to rule out alternative explanations for our main findings, we tested a series of additional models. Considering that it is also conceivable that employees' positive self-beliefs (i.e., personal resources) enhance their work engagement that in turn may boost leaders' transformational characteristics via contagion mechanisms, we tested the alternative hypothesis that employees' day-level work engagement mediates the relationship between day-level personal resources and leaders day-level transformational style. Multilevel analyses rejected this alternative hypothesis, since work engagement (the mediator) was not significantly related to transformational leadership, when the predictors and control variables were taken into account $(\gamma=.199$, $S E=.132, t=1.51, n s)$. These findings suggest that the sequence of effects proposed by our Hypotheses 2 and 3 , and supported by our findings provides a better explanation of the mechanisms under study.

\section{Discussion}

The present diary study investigated whether daily transformational leadership has a positive effect on employees' daily work engagement through the enhancement of employees' personal resources (i.e., self-efficacy and optimism). Results supported the positive relationship between day-level transformational leadership and day-level work engagement, as well as the role of day-level optimism as a full mediator in this relationship. However, the mediating role of self-efficacy in the relationship between transformational leadership style and work engagement was not supported.

The present study makes three important contributions. First, previous research showed that resources, like quality coaching (Xanthopoulou et al., 2007), contribute to the work engagement of employees. To the best of our knowledge, the present study is one of the first to investigate whether the transformational leadership style influences the level of work engagement of the employee through the enhancement of personal resources. In a similar vein, a recent study by Zhu et al. (2009) has also focused on the relationship between transformational leadership and employees' work engagement. These researchers proposed and showed that transformational leadership is related to follower work engagement, particularly when the follower is creative, innovative and proactive. The added value of the present study is that it helps to unfold the psychological mechanisms that underlie the transformational leadership-work engagement relationship, rather than the factors that determine the magnitude of this relationship.

Second, the diary design of the present study allowed investigating fluctuations of the study variables over the course of a working week. Such a design offers the opportunity to capture work events and experiences as they unfold in the work environment (Ilies, Schwind, \& Heller, 2007). Thus, the present results enhance our understanding of the antecedents of real-time work engagement. For instance, by examining day-level transformational leadership style as an antecedent of day-level work engagement, we gain more insight in the role of the leader in the daily process that explains employee engagement at work. Furthermore, support for the proposed psychological processes at the within-person level provides strong evidence for the homology of the relationships across levels of analysis that adds to the parsimony and external validity of the theoretical assumptions under study (Chen et al., 2005; Kozlowski \& Klein, 2000).

Finally, the current study contributes to the leadership literature. Most research on leadership has focused on the organizational outcomes of a specific leadership style, such as performance and efficiency (Harter, Schmidt, \& Hayes, 2002; Howell \& Avolio, 1993). The present study demonstrates that daily fluctuations in transformational leadership may also influence employees' self-beliefs (i.e., personal resources) and work experiences (i.e., work engagement). Employees become more engaged to their work, when their supervisor is able to boost their optimism through his/her transformational leadership style. These results imply that personal resources and work engagement may be important in explaining the transformational leadership-performance link, considering the strong positive link between work engagement and performance (Xanthopoulou et al., 2009a, 2008). Future studies should provide evidence for this latter process. 


\subsection{The role of self-efficacy}

We predicted that a transformational leadership style would enhance work engagement through the mediation of self-efficacy at the day-level. In line with earlier studies that found that a transformational supervisor may enhance employees' self-efficacy beliefs (Kark, Shamir, \& Chen, 2003; Shamir et al., 1993), we expected that transformational leaders, by increasing followers' confidence in their abilities to attain difficult goals (i.e., self-efficacy) would enhance followers' work engagement. However, this hypothesis did not receive statistical support from our data, since transformational leadership had no effect on self-efficacy.

Nevertheless, it is interesting to note that the results of the present study supported the relationship between day-level self-efficacy and day-level work engagement, thus replicating previous findings both at the between-person level (see, for example, Llorens et al., 2007; Xanthopoulou et al., 2007), as well as the within-person level (Xanthopoulou et al., 2009a, 2008). This clearly suggests that self-efficacy is an important personal resource that may contribute to work engagement. However, the process that explains what stimulates self-efficacy in a work setting and consequently, how self-efficacy enhances work engagement needs further investigation.

\subsection{The role of optimism}

Our analyses showed that optimism fully mediates the relationship between transformational leadership and work engagement on a day-level. Thus, on days that the leader applies more evidently the values of the transformational style (by inspiring, motivating and paying special attention to the needs of the employees), he/she enhances employees' optimism. An employee, who feels optimistic about achieving the work goals, is involved and willing to go the extra mile. This finding is in line with a previous study by Xanthopoulou et al. (2009a) who found that quality coaching from the supervisor (operationalized as a job resource) enhanced employees' optimism. This in turn, contributed positively to their work engagement, because employees who received quality coaching from their supervisor (e.g., help with problems they face or well-directed feedback) may have felt more optimistic regarding their future at work.

\subsection{Limitations of the present study}

There are some limitations that need to be addressed. The present study is solely based on self-reports, which are known to have certain limitations such as faking or answering in a social desirable way. By controlling for general levels of work engagement and personal resources and for day-level of job resources in our main analyses, we could indirectly rule out potential biasing effects due to positive affectivity within our sample that may have inflated our study findings. Additionally, we performed a Harman's single factor test to examine whether common method bias was a serious problem in our study (Podsakoff, MacKenzie, Lee, \& Podsakoff, 2003). We did this for the general questionnaire and for each of the five diary surveys separately. Results of item-level principal components analyses with varimax rotation resulted in the expected factors, while in all six analyses the first factor never explained the majority of the total explained variance. These results suggest that common method bias is not particularly threatening in the present study.

A second limitation is that we did not control for daily mood in our analyses. However, we did control for employees' day-levels of job resources in an attempt to rule out potential "good-day" effects. Controlling for day-levels of job resources is particularly crucial in this respect, because job resources have been found to function as triggers of positive mood at work (Schaufeli \& van Rhenen, 2006), and are important predictors of work engagement (Bakker \& Demerouti, 2008). Next, it may be argued that the fact that data were collected only from two different organizations, namely a temporary work agency and an industrial consultancy firm, restricts the generalizability of the results. However, it is important to note that the main purpose of the present study was to examine the psychological processes that explain work engagement and not to compare samples or mean scores, where the use of representative samples is of crucial importance. A fourth limitation of the present study is that the transformational leadership style of each leader was rated only by one subordinate. In future studies it would be worthwhile to ask several employees to rate their leader on his/her respective leadership style in order to get more objective ratings.

Finally, little is known about the effects of a diary study design on participants' responses (Bolger, Davis, \& Rafaeli, 2003). The participants had to complete the same survey for five consecutive days. Although we tried to keep the diary survey as short as possible, it is possible that participants filled out the survey in a habitual way after a few days. Nevertheless, if habituation effects were a serious problem in our study, we would not find significant within-person fluctuations in the day-level variables because participants would answer in the same way every day. As explained in the results section, the intra-class correlations for day-level work engagement, day-level transformational leadership style, day-level optimism, and day-level self-efficacy were all below .37, indicating significant amounts of within-person variation in the answers across the five days. Thus, habituation effects are important to consider in diary studies, but do not seem to affect the results of the present study substantially.

\subsection{Practical implications and conclusion}

The results of this study demonstrate that a resourceful work environment, as created by transformational leaders, is an important prerequisite for an employee to be engaged. The transformational style of the supervisor seems to be highly important, because it boosts employees' optimism and in turn enhances their work engagement. Thus, it might be worthwhile for organizations to invest in transformational leadership training for their leaders. There is research that shows that it is possible to 
train leaders in the transformational leadership style (Barling et al., 1996; Bass, 1999). The experimental study of Barling et al. found that their transformational leadership training had an effect on the perception of the subordinates. They perceived their managers as higher on intellectual stimulation, charisma, and individual consideration than subordinates of managers in the control group, who received no training.

Furthermore, it is conceivable that the positive effect of transformational leadership does not stop after the enhancement of work engagement, but that it may also enhance employees' performance. Since transformational leaders encourage their employees to 'perform beyond their own expectations', it is likely that their followers will perform better. Many studies have confirmed the link between transformational leadership and employee performance (see for example Harter et al., 2002; Howell \& Avolio, 1993; McColl-Kennedy \& Anderson, 2002; Yammarino \& Bass, 1990). For example, a recent diary study by Xanthopoulou et al. (2009a) showed evidence for the relationship between work engagement and objective performance at the day-level. Namely, they found that state quality coaching from the supervisor (a dimension of transformational leadership) positively affected the financial returns in a fast-food company, through state work engagement. Taken together, findings suggest that by stimulating and inspiring, transformational supervisors not only enhance employees' resources and work engagement but they may also enhance their job performance. This in turn, may contribute to a flourishing organization in terms of human capital and productivity.

\section{References}

Avery, D. R., McKay, P. F., \& Wilson, D. C. (2007). Engaging the aging workforce: The relationship between perceived age similarity, satisfaction with coworkers, and employee engagement. The Journal of Applied Psychology, 92, 1542-1556.

Avolio, B. J., \& Bass, B. M. (1995). Individual consideration viewed at multiple levels of analysis: A multilevel framework for examining the diffusion of transformational leadership. The Leadership Quarterly, 6, 199-218.

Bakker (2009). Building engagement in the workplace. In C. Cooper \& R. Burke (Eds.), The peak performing organization (pp. 50-72). London: Routledge.

Bakker, A. B., \& Demerouti, E. (2008). Towards a model of work engagement. Career Development International, 13, $209-223$.

Bakker, A. B., Schaufeli, W. B., Leiter, M. P., \& Taris, T. W. (2008). Work engagement: An emerging concept in occupational health psychology. Work E Stress, 22, $187-200$

Bakker, A. B., Westman, M., \& van Emmerik, I. J. H. (2009). Advancements in crossover theory. Journal of Managerial Psychology, $24,206-219$.

Bandura, A. (1977). Social learning theory. Englewood Cliffs, NJ: Prentice Hall.

Bandura, A. (1997). Self-efficacy: The exercise of control. New York: Freeman.

Barling, J., Weber, T., \& Kelloway, K. (1996). Effects of transformational leadership training on attitudinal and financial outcomes: A field experiment. The Journal of Applied Psychology, 81, 827-832.

Baron, R. M., \& Kenny, D. A. (1986). The moderator-mediator variable distinction in social psychological research: Conceptual, strategic, and statistical considerations. Journal of Personality and Social Psychology, 51, 1173-1182.

Bass, B. M. (1985). Leadership performance beyond expectations. New York: Academic Press.

Bass, B. M. (1999). Two decades of research and development in transformational leadership. European Journal of Work and Organizational Psychology, 8, 9-32.

Bass, B. M., \& Avolio, B. J. (1990). Improving organizational effectiveness through transformational leadership. Thousand Oaks: Sage Publications.

Bolger, N., Davis, A., \& Rafaeli, E. (2003). Diary methods: Capturing life as it is lived. Annual Review of Psychology, 54, 579-616.

Bono, J. E., Jackson Foldes, H., Vinson, G., \& Muros, J. P. (2007). Workplace emotions: The role of supervision and leadership. The Journal of Applied Psychology, 92, $1357-1367$.

Bono, J. E., \& Judge, T. A. (2004). Personality and transformational and transactional leadership: A meta-analysis. The Journal of Applied Psychology, 89, 901 -910.

Bycio, P., Hackett, R. D., \& Allen, S. J. (1995). Further assessment of Bass's (1985) conceptualization of transactional and transformational leadership. The Journal of Applied Psychology, 80, 468-478.

Chemers, M. M. (2000). Leadership research and theory: A functional integration. Group Dynamics: Theory, Research, and Practice, 4, $27-43$.

Chen, G., Bliese, P. D., \& Mathieu, J. E. (2005). Conceptual framework and statistical procedures for delineating and testing multilevel theories of homology. Organizational Research Methods, 8, 375-409.

Deci, E. L., Koestner, R., \& Ryan, R. M. (1999). A meta-analytic review of experiments examining the effects of extrinsic rewards on intrinsic motivation. Psychological Bulletin, 125, 627-668.

den Hartog, D. N., Koopman, P. L., \& van Muijen, J. J. (1997). Inspirerend leiderschap in organisaties. Schoonhoven: Academic Service.

Dierdorff, E. C., \& Ellington, J. K. (2008). It's the nature of work: Examining behavior-based sources of work-family conflict across occupations. The Journal of Applied Psychology, 93, 883-892.

George, J. M. (1991). State or trait: Effects of positive mood on prosocial behaviors at work. The Journal of Applied Psychology, $76,299-307$.

Halbesleben, J. R. B. (2010). A meta-analysis of work engagement: Relationships with burnout, demands, resources and consequences. In A. B. Bakker \& M.P. Leiter (Eds.), Work engagement: The essential in theory and research (pp. 102-117). New York: Psychology Press.

Harter, J. K., Schmidt, F. L., \& Hayes, T. L. (2002). Business-unit level relationship between employee satisfaction, employee engagement, and business outcomes: A meta-analysis. The Journal of Applied Psychology, 87, 268-279.

Hatfield, F., Cacioppo, J., \& Rapson, R. L. (1994). Emotional contagion. Paris: Cambridge University Press.

Hauge, L. J., Skogstad, A., \& Einarsen, S. (2007). Relationships between stressful work environment and bullying: Results of a large representative study. Work E Stress, 21, 220-242.

Hobfoll, S. E., Johnson, R. J., Ennis, N. E., \& Jackson, A. P. (2003). Resource loss, resource gain, and emotional outcomes among inner-city women. Journal of Personality and Social Psychology, 84, 632-643.

House, R. J., \& Howell, J. M. (1992). Personality and charismatic leadership. The Leadership Quarterly, 3, 81-108.

Howell, J. M., \& Avolio, A. J. (1993). Transformational leadership, transactional leadership, locus of control, and support for innovation: Key predictors of consolidated-business-unit performance. The Journal of Applied Psychology, 78, 891-902.

Hox, J. (2002). Multilevel analysis: Techniques and applications. London: Lawrence Erlbaum Associates, Publishers.

Ilies, R., Schwind, K. M., \& Heller, D. (2007). Employee well-being: A multilevel model linking work and nonwork domains. European Journal of Work and Organizational Psychology, 16, 326-341.

Kark, R., Shamir, B., \& Chen, G. (2003). The two faces of transformational leadership: Empowerment and dependency. The Journal of Applied Psychology, 88, $246-255$

Kirkpatrick, S. A., \& Locke, E. A. (1996). Direct and indirect effects of three core charismatic leadership components on performance and attitudes. The Journal of Applied Psychology, 81, 36-51.

Kozlowski, S. W. J., \& Klein, K. J. (2000). A multilevel approach to theory and research in organizations: Contextual, temporal, and emergent processes. In K. J. Klein \& S.W.J. Kozlowski (Eds.), Multilevel theory, research, and methods in organizations: Foundations, extensions, and new directions (pp. 3-90). San Francisco: Jossey-Bass 
Llorens, S., Schaufeli, W. B., Bakker, A. B., \& Salanova, M. (2007). Does a positive gain spiral of resources, efficacy beliefs and engagement exist? Computers in Human Behavior, 23, 825-841.

Luthans, F., Avey, J. B., Avolio, B. J., Norman, S., \& Combs, G. M. (2006). Psychological capital development: A micro intervention. Journal of Organizational Behavior, 27, 387-393.

Luthans, F., \& Youssef, C. M. (2007). Emerging positive organizational behavior. Journal of Management, 33, $321-349$.

Maas, C. J. M., \& Hox, J. J. (2005). Sufficient sample sizes for multilevel modeling. Methodology, 1, 86-92.

Macey, W. H., \& Schneider, B. (2008). The meaning of employee engagement. Industrial and Organizational Psychology, 1, 3-30.

McColl-Kennedy, J. R., \& Anderson, R. D. (2002). Impact of leadership style and emotions on subordinate performance. The Leadership Quarterly, 13, 545-559.

Pajares, F. (2002). Overview of social cognitive theory and of self-efficacy. Retrieved March, 10, 2008, from http://www.emory.edu/EDUCATION/mfp/eff.html

Podsakoff, P. M., MacKenzie, S. M., Lee, J., \& Podsakoff, N. P. (2003). Common method variance in behavioral research: A critical review of the literature and recommended remedies. The Journal of Applied Psychology, 88, 879-903.

Rashbash, J., Browne, W., Healy, M., Cameron, B., \& Charlton, C. (2000). MLwiN (Version1.10.006): Interactive software for multilevel analysis. London: Multilevel Models Project, Institute of Education, University of London.

Schaufeli, W. B., \& Bakker, A. B. (2004). Job demands, job resources, and their relationship with burnout and engagement: A multi-sample study. Journal of Organizational Behavior, 25, 293-315.

Schaufeli, W. B., \& Bakker, A. B. (2010). Defining and measuring work engagement: Bringing clarity to the concept. In A. B. Bakker \& M.P. Leiter (Eds.), Work engagement: A handbook of essential theory and research (pp. 10-24). New York: Psychology Press.

Schaufeli, W. B., Bakker, A. B., \& Salanova, M. (2006). The measurement of work engagement with a short questionnaire: A cross-national study. Educational and Psychological Measurement, 66, 701-716.

Schaufeli, W. B., \& Salanova, M. (2007). Work engagement: An emerging psychological concept and its implications for organizations. In S. W. Gilliland, D. D. Steiner, \& D. P. Skarlicki (Eds.), Research in social issues in management: Managing social and ethical issues in organizations (pp. 135-177). Greenwich, CT: Information Age Publishers.

Schaufeli, W. B., \& van Rhenen, W. (2006). Over de rol van positieve en negatieve emoties bij het welbevinden van managers: Een studie met de Job-related Affective Well-being Scale (JAWS) [About the role of positive and negative emotions in managers' well-being: A study using the Job-related Affective Wellbeing Scale (JAWS)]. Gedrag E' Organisatie, 19, 323-344.

Scheier, M. F., \& Carver, C. S. (1992). Effects of optimism on psychological and physical well-being: Theoretical overview and empirical update. Cognitive Therapy and Research, 16, 201-228.

Scheier, M. F., Carver, C. S., \& Bridges, M. W. (1994). Distinguishing optimism from neuroticism (and trait anxiety, self-mastery, and self-esteem): A re-evaluation of the Life Orientation Test. Journal of Personality and Social Psychology, 67, 1063-1078.

Schwartzer, R., \& Jerusalem, M. (1995). Generalized self-efficacy scale. In J. Weinman, S. Wright, \& M. Johnston (Eds.), Measures in health psychology: A user's portfolio. Causal and control beliefs. Windsor, UK: NFER-NELSON.

Shamir, B., House, R. J., \& Arthur, M. B. (1993). The motivational effect of charismatic leadership: A self-concept based theory. Organization Science, 4, 577-594.

Skogstad, A., Einarsen, S., Torsheim, T., Aasland, S. M., \& Hetland, H. (2007). The destructiveness of laissez-faire leadership behavior. Journal of Occupational Health Psychology, 12, 80-92.

Sonnentag, S. (2003). Recovery, work engagement, and proactive behaviour: A new look at the interface between nonwork and work. The Journal of Applied Psychology, 88, 518-528.

Sonnentag, S., \& Niessen, C. (2008). Staying vigorous until work is over: The role of trait vigour, day-specific work experiences and recovery. Journal of Occupational and Organizational Psychology, 81, 435-458.

Sonnentag, S., Dormann, C., \& Demerouti, E. (2010). Not all days are created equal: The concept of state work engagement. In A. B. Bakker \& M. Leiter (Eds.), Work engagement: The essential in theory and research (pp. 25-38). New York: Psychology Press.

Stuart, E. (2005). Veranderingsbereidheid door leiderschap. Is leiderschap de sleutel tot succesvol veranderen? Een onderzoek naar de invloed van de stijl van leidinggeven op de veranderingsbereidheid van docenten in het voortgezet onderwijs. [Willingness to change because of leadership. Is leadership the key to successful change? An investigation of the influence of leadership style on the willingness to change by teachers in secondary schools]. Unpublished doctoral dissertation. Vrije Universiteit van Amsterdam: The Netherlands.

van Vugt, M., Jepson, S. F., Hart, C. M., \& de Cremer, D. (2004). Autocratic leadership in social dilemmas: A threat to group stability. Journal of Experimental Social Psychology, 40,1-13.

Xanthopoulou, D., Bakker, A. B., Demerouti, E., \& Schaufeli, W. B. (2007). The role of personal resources in the job demands-resources model. International Journal of Stress Management, 14, 121-141.

Xanthopoulou, D., Bakker, A. B., Demerouti, E., \& Schaufeli, W. B. (2009a). Work engagement and financial returns: A diary study on the role of job and personal resources. Journal of Occupational and Organizational Psychology, 82, 183-200.

Xanthopoulou, D., Bakker, A. B., Demerouti, E., \& Schaufeli, W. B. (2009b). Reciprocal relationships between job resources, personal resources, and work engagement. Journal of Vocational Behavior, 74, 235-244.

Xanthopoulou, D., Bakker, A. B., Heuven, E., Demerouti, E., \& Schaufeli, W. B. (2008). Working in the sky: A diary study on work engagement among flight attendants. Journal of Occupational Health Psychology, 13, 345-356.

Yammarino, F. J., \& Bass, B. M. (1990). Long-term forecasting of transformational leadership and its effects among naval officers: Some preliminary findings. In K. E. Clark \& M.B. Clark (Eds.), Measures of leadership (pp. 151-171). West Orange, NJ: Leadership Library of America.

Yorges, S. L., Weiss, H. M., \& Strickland, O. J. (1999). The effect of leader outcomes on influence, attributions, and perceptions of charisma. The Journal of Applied Psychology, 84, 428-436.

Yukl, G. A. (1989). Leadership in organizations. Englewood Cliffs, NJ: Prentice Hall.

Zhu, W., Avolio, B. J., \& Walumbwa, F. O. (2009). Moderating role of follower characteristics with transformational leadership and follower work engagement. Group and Organization Management, 34, 590-619. 